\title{
Effect of Zn Content on the Physicochemical Characteristics and Photoactivity of ZnO Supported Activated Carbon
}

\author{
IS FATIMAH*, SEPTIAN P. YUDHA, KURNI DWI SOPIANA and DEVI LIA RATNASARI \\ Chemistry Department, Islamic University of Indonesia, Kampus Terpadu UII, \\ Jl. Kaliurang Km 14, Sleman, Yogyakarta, Indonesia. \\ *Corresponding author E-mail: isfatimah@uii.ac.id \\ http://dx.doi.org/10.13005/ojc/320550
}

(Received: September 22, 2016; Accepted: October 16, 2016)

\begin{abstract}
In the present work, synthesis of $\mathrm{ZnO}$ dispersed onto activated carbon $(\mathrm{ZnO} / \mathrm{AC})$ is reported. Synthesis was conducted by using impregnation method by zinc acetate as precursor at varied $\mathrm{Zn}$ content. A systematic characterization of $\mathrm{ZnO} / \mathrm{C}$ materials was performed using $\mathrm{XRD}$, SEM, gas sorption analyzer and diffuse reflectance UV-Visible spectrophotometer. Photoactivity of the materials was studied in phenol removal via photooxidation mechanism. From the study it is confirmed that $\mathrm{ZnO}$ dispersion give acceleration of phenol removal refer to surface area contribution. It is no linear correlation of each physical character to the photocatalytic activity.
\end{abstract}

Keywords: Activated Carbon; Photocatalyst; Photooxidation; ZnO.

\section{INTRODUCTION}

Water and wastewater treatment is still the focus in environmental protection. Contamination of organic and dye compounds in aquatic system get interest refer to its potencies from several industrial activities. Several techniques were developed including adsorption, oxidation and photooxidation method. Among some methods applicable for industrial scale, in recent years photocatalytic degradation of pollutant in aquatic system became the advance technique since it can reduce the cost the treatment due to its reusability ${ }^{1-3}$. The main factor in the system is highly active photocatalyst and one of the potential photocatalyts can be elected, $\mathrm{ZnO}$ materials have attracted much attention due to their excellent optical properties and facile synthesis methods. $\mathrm{ZnO}$ itself has been reported to have activity for photodegradation and photooxidation of some organic molecules ${ }^{4,5,6,7-9}$. Similar to the photocatalytic mechanism of $\mathrm{TiO}_{2}$, the initial step in $\mathrm{ZnO}$ photocatalysis involves the generation of an

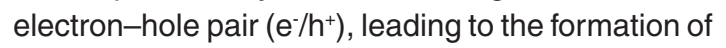
hydroxyl radicals, superoxide radical anions $\left(\mathrm{O}_{2}^{-*}\right)$, 
and hydroperoxy radicals $(\cdot \mathrm{OOH})$ with following equations $^{9}$

$\mathrm{ZnO}+\mathrm{hv} \rightarrow \mathrm{ZnO}\left(\mathrm{h}^{+}+\mathrm{e}^{-}\right)$

$\mathrm{H}_{2} \mathrm{O}_{\text {(ads) }}+\mathrm{h}^{+} \rightarrow \cdot \mathrm{OH}+\mathrm{H}^{+}$

$\mathrm{OH}^{-}+\mathrm{h}^{+} \rightarrow \cdot \mathrm{OH}$

$\mathrm{O}_{2}+\mathrm{e}^{-} \rightarrow \mathrm{O}_{2} \cdot$

$\mathrm{O}_{2}+\mathrm{e}^{-}+\mathrm{H}+\rightarrow \cdot \mathrm{OOH}$

Once targeted organic molecule is attacked, radicals formed will oxidize through the mechanisms. In addition to hydroxyl radicals, superoxide radical and the positive holes are species that also possible to oxidize organic contaminants present at/or near the surface. By the mechanism it is also acceptable that as the adsorption of targeted molecule play important role for further step. With the similar value of band gap energy and chemical stability respect to $\mathrm{TiO}_{2}$, the activity of $\mathrm{ZnO}$ can be improved by attaching onto a stable and high surface area solid such as activated carbon(AC) $)^{3,6}$. Not only by its great specific surface area and low cost, but $A C$ also give synergistic effect on photocatalysis via the strong adsorption properties which is also the controlling factor in photocatalysis ${ }^{10,11}$. From previous research, it is found that the combination of some photocatalyst with $A C$ give synergistic effects ${ }^{2,12}$. There are several methods developed and reported by previous researches. Beside of sol-gel method and the use of organic molecule such as hydrazine as carbon source in the preparation, composite of $\mathrm{ZnO}$ and activated carbon was also proposed to be formed by direct infiltration. Similar approximation was also reported for the synthesis of composite from $\mathrm{ZnO}$ and carbon black. By the hypothetical condition of $\mathrm{ZnO}$ immobilizing onto $A C$, we report an easy method to obtain ZnO/AC composite photocatalytic material. For photocatalytic purposes, the investigation on the effect of $\mathrm{ZnO}$ in At the same time, the photocatalytic efficiency of $\mathrm{ZnO} / \mathrm{AC}$ composite photocatalytic material was characterized by the effect of $\mathrm{Zn}$ content on the photocatalytic activity. The correlation of $\mathrm{Zn}$ content to the physicochemical character and photocatalytic activity and also some factors affecting the photocatalytic activity were studied.

\section{MATERIALS AND METHOD}

Zinc acetate dehydrate and activated carbon; the main materials for catalyst dihydrate preparation, and phenol as target molecule were provided by Merk-Millipore and were used without further purification.

The $\mathrm{ZnO} / \mathrm{AC}$ was prepared as follows : zinc acetate dehydrate solution was mixed with activated carbon powder with continuous stirring for a night at

Table 1: Physicochemical character of materials

\begin{tabular}{lcccc}
\hline Sample & $\begin{array}{c}\text { Zn } \\
\text { content (\%) }\end{array}$ & $\begin{array}{c}\text { Pore } \\
\text { Radius (Å) }\end{array}$ & $\begin{array}{c}\text { Specific surface } \\
\text { area }\left(\mathbf{m}^{2} / \mathbf{g}\right)\end{array}$ & $\begin{array}{c}\text { Pore Volume } \\
\mathbf{( c c / g )}\end{array}$ \\
\hline AC & n.d & 16.79 & 617.684 & $5.187 \times 10^{-1}$ \\
ZnO/AC-2.5 & 2.57 & 17.48 & 556.644 & $4.865 \times 10^{-1}$ \\
ZnO/AC-5.0 & 5.12 & 20.71 & 322.588 & $3.341 \times 10^{-1}$ \\
ZnO/AC-7.5 & 7.80 & 24.24 & 176.631 & $2.141 \times 10^{-1}$ \\
ZnO/AC-10.0 & 9.98 & 22.24 & 205.768 & $2.288 \times 10^{-1}$ \\
\hline
\end{tabular}

Table 2: Initial rate of phenol removal over varied treatment and catalyst

\begin{tabular}{lccccc}
\hline Treatment & \multicolumn{5}{c}{ Initial rate (10-2ppm/mins) } \\
& AC & ZnO/AC-2.5 & ZnO/AC-5.0 & ZnO/AC-7.5 & ZnO/AC-10.0 \\
& & & & & \\
\hline Photocatalysis & 2.23 & 36.61 & 44.64 & 41.50 & 41.14 \\
Adsorption & 2.29 & 1.88 & 1.85 & 1.78 & 1.85 \\
Photooxidation & 19.37 & 41.10 & 77.81 & 48.12 & 67.10 \\
Photolysis & 2.84 & 2.84 & 2.84 & 2.84 & 2.84 \\
\hline
\end{tabular}


room temperature. The concentration of zinc acetate dehydrate was set up to the theoretical $\mathrm{Zn}$ content of $2.5 ; 5.0 ; 7.5$ an $10.010 \%$ wt. The sample was filtered and washed several times with distilled water until the $\mathrm{pH}$ values of the solution reached neutral $\mathrm{pH}$, and then dried at $1108 \mathrm{C}$ for $24 \mathrm{~h}$ in an oven. The dried sample was clacined at the temperature of $400^{\circ} \mathrm{C}$ and the solid obtained is designed as $\mathrm{ZnO} / \mathrm{AC}$. Refer to varied $\mathrm{Zn}$ content, the $\mathrm{ZnO} / \mathrm{SACs}$ obtained were labeled $\mathrm{ZnO} / \mathrm{C}-2.5 ; \mathrm{ZnO} / \mathrm{C}-5.0, \mathrm{ZnO} / \mathrm{C}-7.5$ and $\mathrm{ZnO} / \mathrm{C}-10.0$ respectively.

Scanning electron microscope-Energy dispersive X-ray spectroscopy (SEM-EDX JEOL) was used to investigate the morphology and chemical composition of the samples. XRD analysis was performed using X-ray diffractometer (XRD, Rigaku Bench Top-10) with Ni-filtered $\mathrm{Cu}$-Ka radiation. The

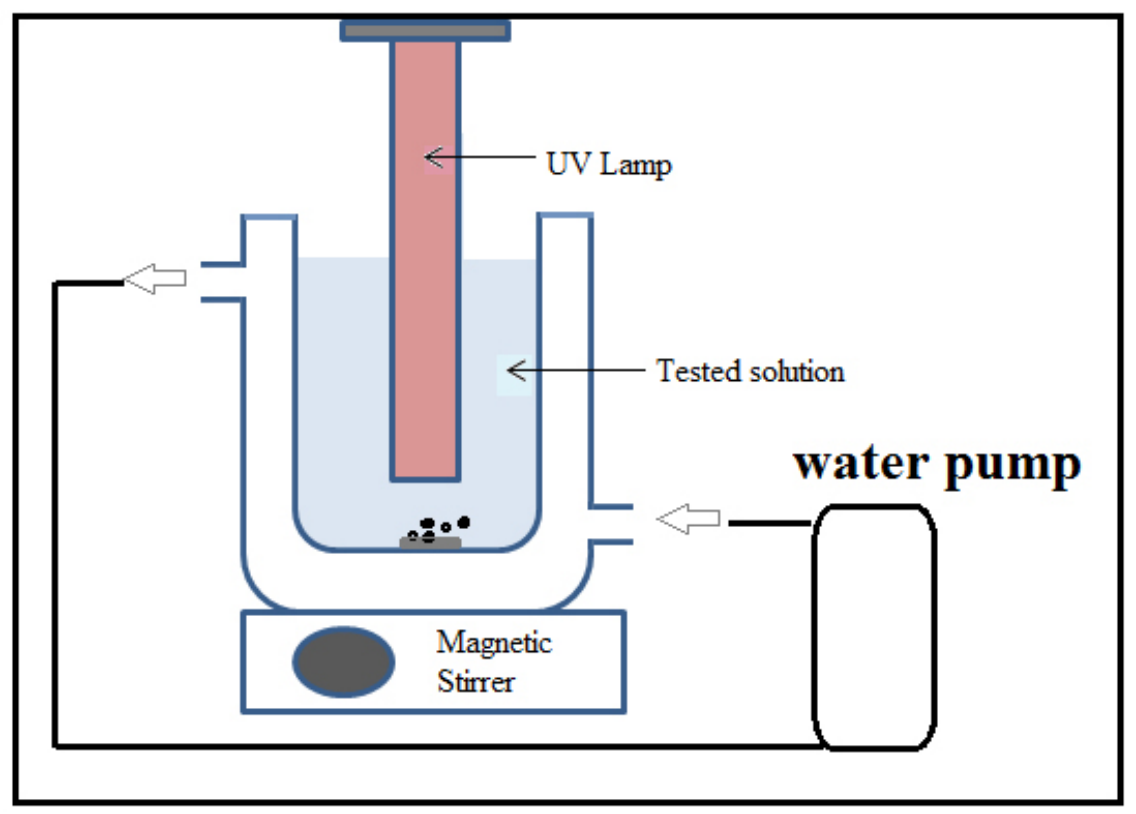

Fig. 1: Scheme of Photocatalytic reactor

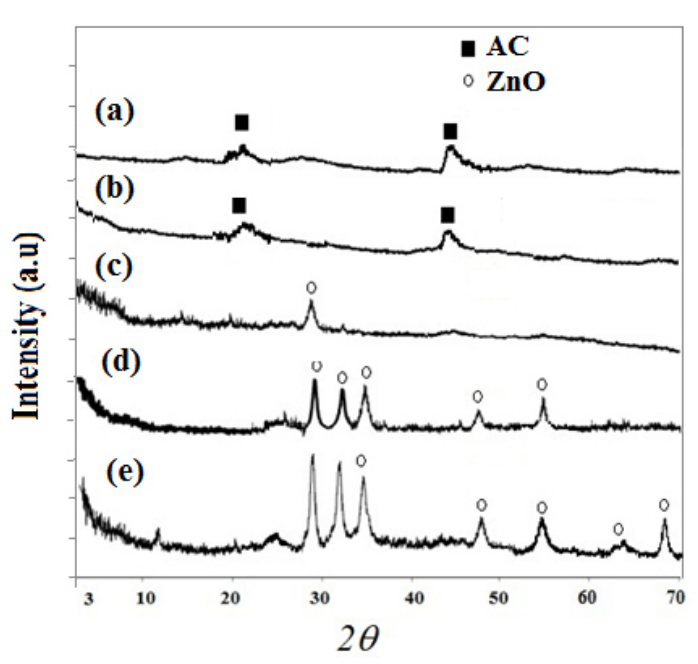

Fig. 2: XRD pattern of (a) AC (b) Zn/AC-2.5 (c) $Z n / A C-5.0$ (d) Zn/AC-7.5 (e) $Z n / A C-10.0$ specific surface area and pore structure of the $\mathrm{ZnO} /$ AC photocatalysts were measured by the BrunauerEmmett-Teller (BET) method using a Micromeritics ASAP 2010 apparatus. Band gap energy of the materials was analyzed by using diffuse reflectance UV-Visible JASCO series. VG 220i-XL EscaLab was utilized for x-ray photoelectrone spectroscopy(XPS) spectra identification.

\section{Photocatalytic Study}

Photocatalytic study of the photocatalysts were performed in phenol photooxidation. For photocatalytic testing a batch photoreactor with the scheme in Figure 1 was utilized. For each experiment, $0.2 \mathrm{~g} \mathrm{ZnO} / \mathrm{AC}$ photocatalyst was mixed with $500 \mathrm{~mL}$ of phenol solution in a batch reactor complimented with UV-lamp immersed in solution. During the test, the solution was stirred at $150 \mathrm{rpm}$. 
In order to evaluate the photocatalytic activity varied methods were tested involving:

Adsorption : adsorbent addition without UV expose and without $\mathrm{H}_{2} \mathrm{O}_{2}$ as oxidant,

Photolysis : without adsorbent, addition with UV expose and without $\mathrm{H}_{2} \mathrm{O}_{2}$ as oxidant

Photocatalysis : adsorbent addition with UV expose and without $\mathrm{H}_{2} \mathrm{O}_{2}$ as oxidant, and

Photooxidation : adsorbent addition with UV expose and $\mathrm{H}_{2} \mathrm{O}_{2}$ as oxidant.

The amount of phenol (mg/L) at each time interval was calculated according to gas chromatography (GC) analysis. A Buck Scientific Gas Chromatography instrument was used.

Percentage of phenol removal is calculated based on GC responses with the following equation:

Phenol removal $(\%)=100\left(1-\frac{[\text { phenol }]_{\text {solution }}}{[\text { phenol }]_{\text {initial }}}\right)$

\section{RESULT AND DISCUSSION}

\section{Material Preparation}

In order to detect the formed $\mathrm{ZnO}$ on $\mathrm{AC}$ surface, XRD analysis was performed and the data presented in Figure 2. AC show broad and low intensity peaks at around $\mathrm{q}=21.8^{\circ}$ and $44^{\circ}$ as reflections of the graphitic structure of $\mathrm{AC}^{13}$. Except for $\mathrm{ZnO} / \mathrm{AC}-2.5$ the presence of $\mathrm{ZnO}$ can be detected by the peaks of the $\mathrm{ZnO}$ nanoparticles wurtzite single phase ZnO (JCPDS Card No. 36-1451) at the $2 q$ of and there is no characteristic peaks of other impurities such as $\mathrm{Zn}(\mathrm{OH})_{2}$ detected in the diffractograms.

Based on the maximum intensity of the peak, the average diameter of the particles calculated using Scherrer formula is around $25 \mathrm{~nm}$. The SEM image (Figure 3) of the $\mathrm{ZnO} / \mathrm{AC}$ samples indicates some aggregates formed on surface and the higher $\mathrm{Zn}$ content the more aggregates formed.

The profiles data is linearly correlated with the surface profile data in Table 1 in which the
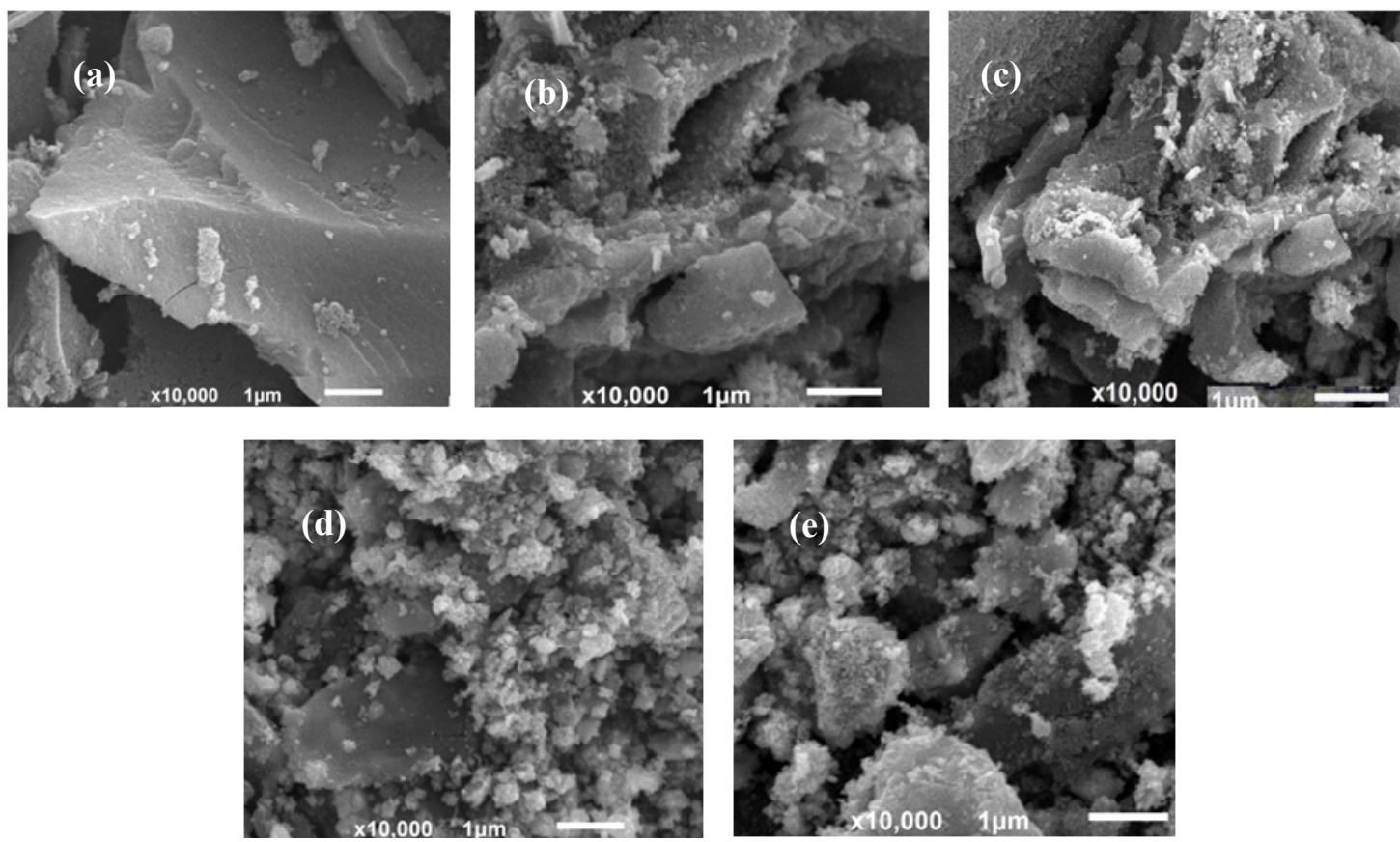

Fig. 3: SEM Profile of (a) AC (b) Zn/AC-2.5 (c) Zn/AC-5.0 (d) Zn/AC-7.5 (e ) Zn/AC-10.0 
calculated specific surface area, pore volume and pore radius based on $\mathrm{N}_{2}$ adsorption-desorption data in Figure 4.

In general, increasing Zn content contributes to the decreasing specific surface area and pore volume data and getting minimum at $\mathrm{ZnO} / \mathrm{AC}-7.5$ but then those parameter for $\mathrm{ZnO} / \mathrm{AC}-10.0$ are higher than for $\mathrm{ZnO} / \mathrm{AC}-7.5$. The trend is related
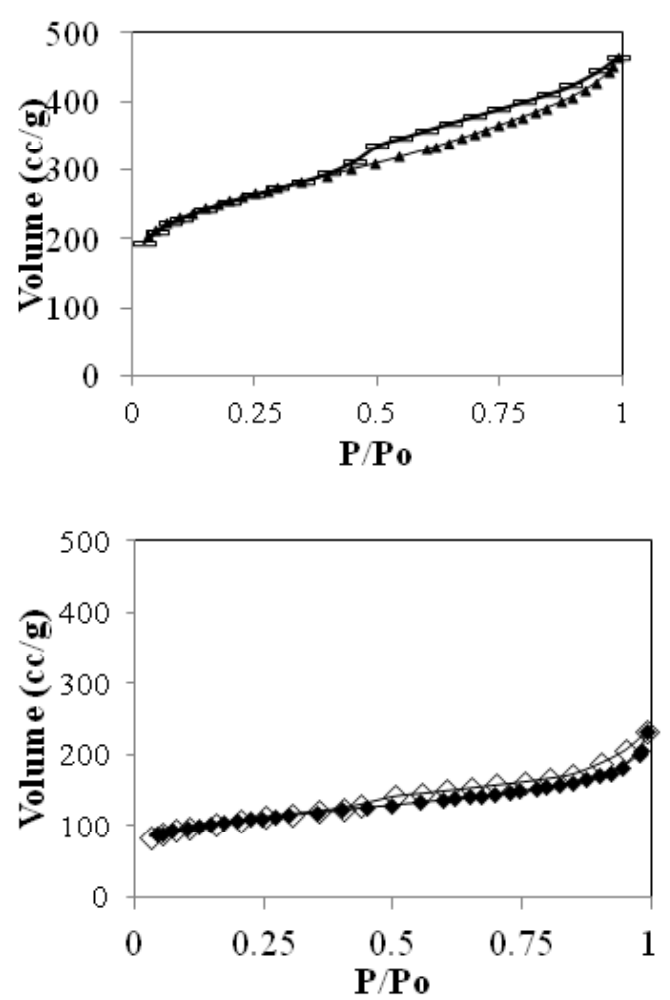

to the formation of aggregates dominantly blocked the pores of activated carbon but then at the $\mathrm{Zn}$ percentage of $10 \%, \mathrm{ZnO}$ aggregates create the accessible surface for adsorbate. The chemical interaction of $\mathrm{Zn}, \mathrm{O}$ and $\mathrm{C}$ is depicted by XPS spectra of $\mathrm{ZnO} / \mathrm{AC}-5$ in Figure 5.

XPS survey spectra of the composite shows three main peaks as the proof of $\mathrm{ZnO} / \mathrm{AC}$
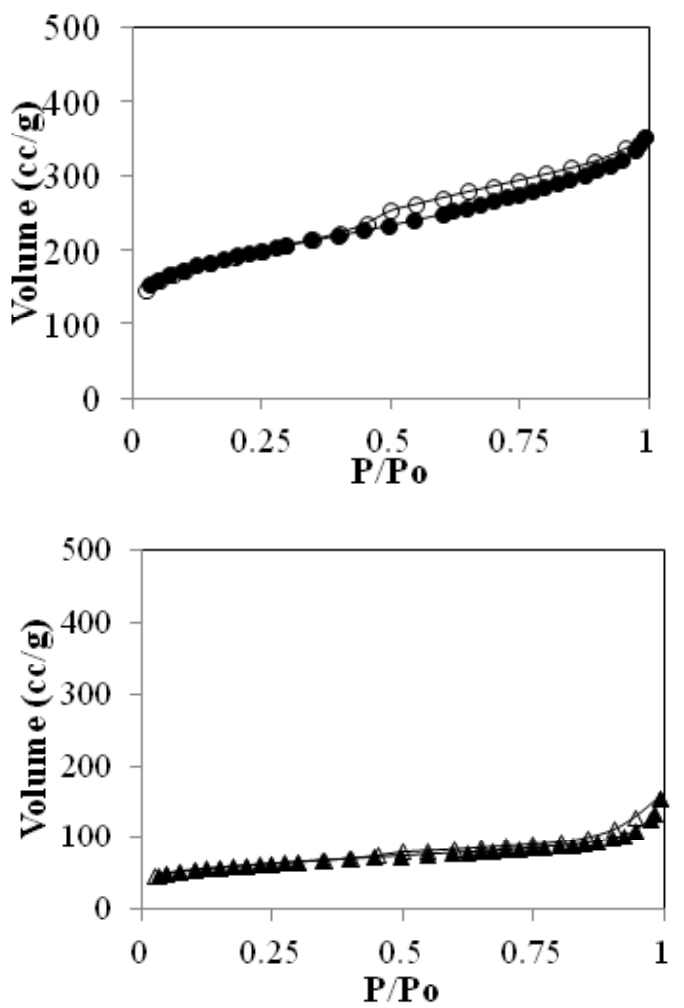

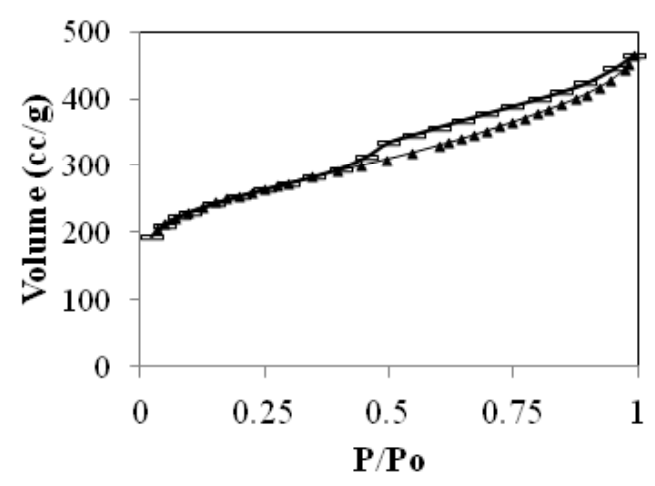

Fig. 4: Adsorption-desorption Profile of (a) AC (b) Zn/AC-2.5

(c) Zn/AC-5.0 (d) Zn/AC-7.5 (e ) Zn/AC-10.0 
composite, one peak at $532 \mathrm{eV}$ corresponding to $\mathrm{O} 1 \mathrm{~s}$, one peak at $285 \mathrm{eV}$ corresponding to $\mathrm{C} 1 \mathrm{~s}$, and two peaks at 1020-1045 eV corresponding to $\mathrm{Zn} 2 \mathrm{p}$. High resolution scans of the XPS spectra of $\mathrm{Zn} 2 \mathrm{p}$ (1020.2 and $1045.3 \mathrm{eV}$ ) are correspond to $\mathrm{Zn}$ $2 p 3 / 2$ and $Z n$ 2p1/2which subhect to $Z n-O$ bonding in $\mathrm{ZnO}$. Futhermore the spectra at 0.500 and 0.506 keV are correspond to $\mathrm{Zn}$ LMM auger peak.
As different particle size formed as function of the $\mathrm{Zn}$ content, the effect of $\mathrm{Zn}$ content on the band gap energy is presented by DRUV-Vis spectra (Figure 6). From the spectra it can be concluded that the higher $\mathrm{Zn}$ content in the composite contribute to the red shift with the increasing intensity. This phenomenon is the quantization size effect which caused the longer wavelength due to

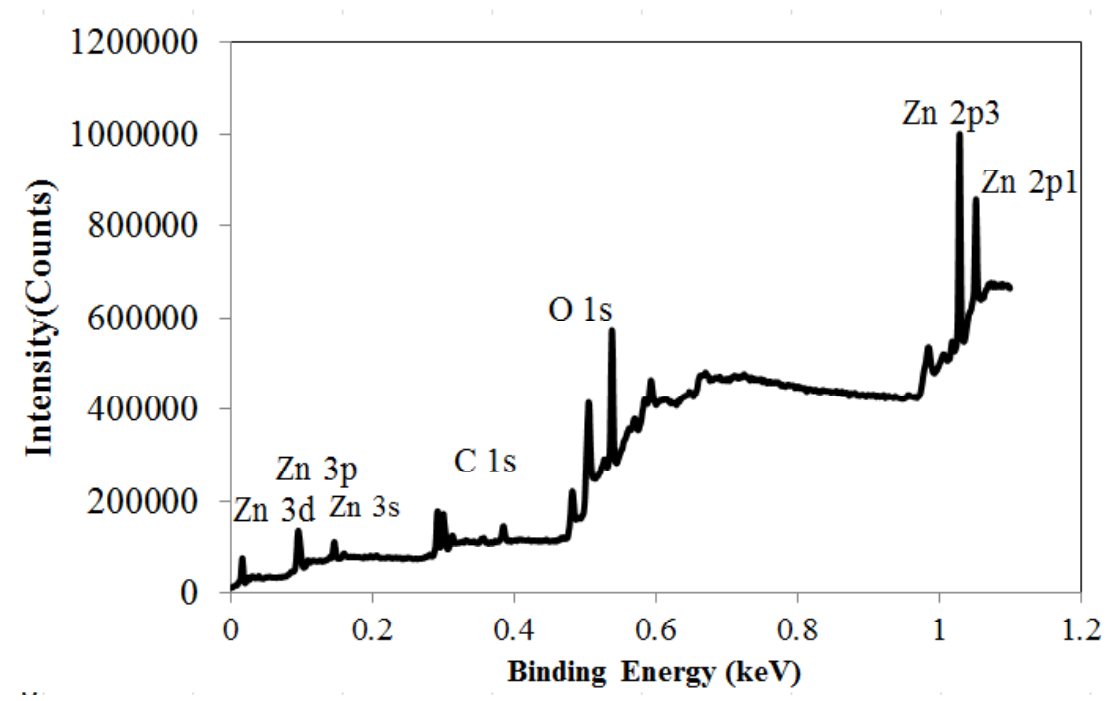

Fig. 5: XPS spectra of Zn/AC-5.0

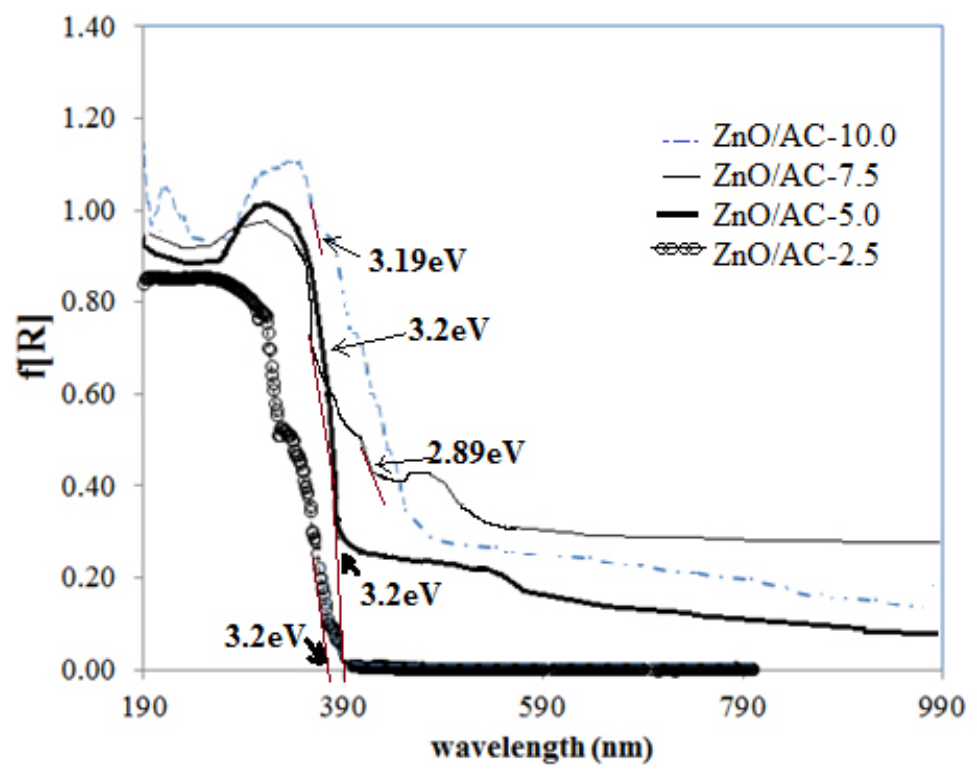

Fig. 6: DRUV-Vis spectra of materials 
large particle size. Hence the light absorption and charge separation were significantly enhanced. The same trend was reported in the synthesis of $\mathrm{ZnO}$ nanocomposites ${ }^{14}$. As effect of the formation of different particle size of $\mathrm{ZnO}$, multiple band gap values are found for $\mathrm{ZnO} / \mathrm{AC}-7.5$ and $\mathrm{ZnO} / \mathrm{AC}-10.0$ (Table 1).

\section{Photocatalytic Activity}

Photocatalytic activity of the materials was tested in varied process; adsorption, photolysis, photocatalysis, and photooxidation. Figure 7 presents the different kinetic of phenol removal over varied process over ZnO/AC-5.0 compared to AC and calculated initial rate of phenol removal by prepared materials is listed in Table 2.
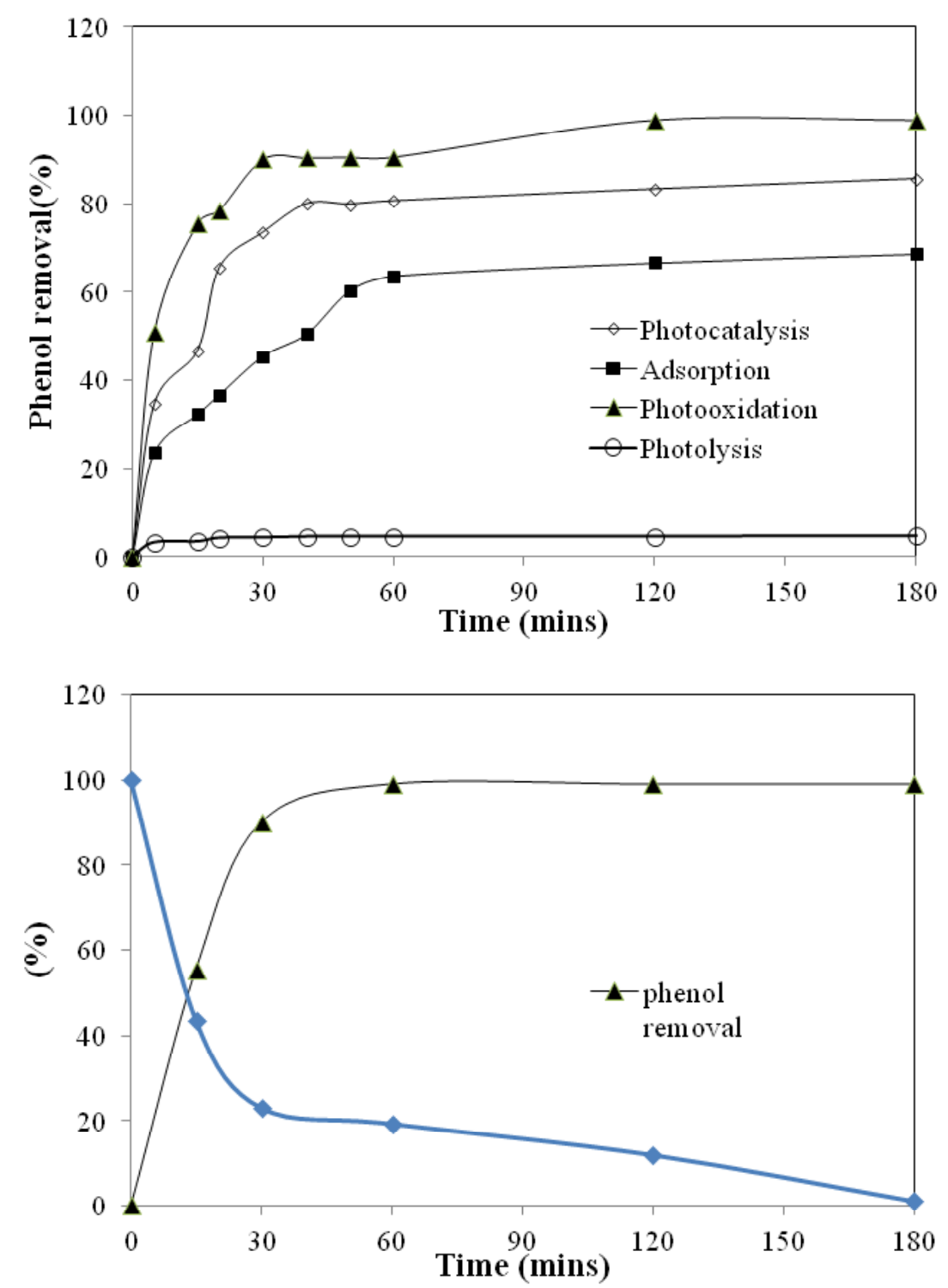

Fig. 7: (a) Kinetic of phenol removal over varied treatments (Catalyst dosage: $\mathbf{5}$ g/L; initial concentration: 10ppm, pH = 7); (b) Phenol reduction and COD reduction (Catalyst: $\mathrm{Zn/AC-5.0;}$ Catalyst dosage: $5 \mathrm{~g} / \mathrm{L}$; initial concentration: 10ppm, $\mathrm{pH}=7$ ) (Condition: Catalyst dosage: $5 \mathrm{~g} / \mathrm{L}$; initial concentration: $10 \mathrm{ppm}, \mathrm{pH}=7$ ) 


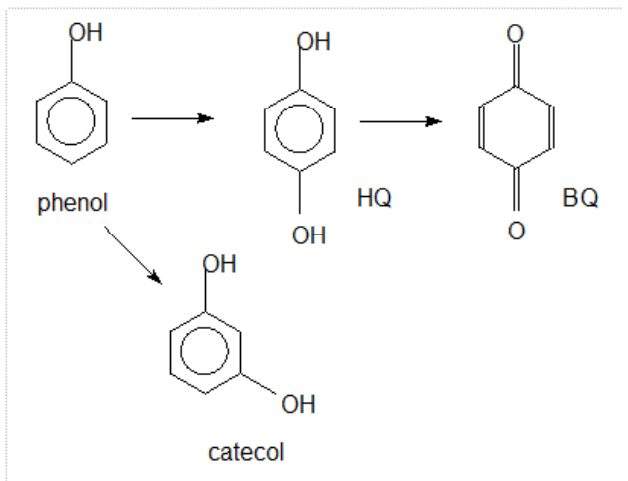

Degradation of phenol over photooxidation has highest rate as shown by rapid degradation percentage as increasing time of the treatment. In general the degradation rate over varied treatment is in following order: photooxidation> photocatalysis $>$ adsorption > photolysis. From adsorption process it is noted that there is no signicant difference by varying photocatalyst even there is significant difference of specific surface area as main factor in adsorption. It may related to the small amount of the adsorbent. By the additional UV expose in
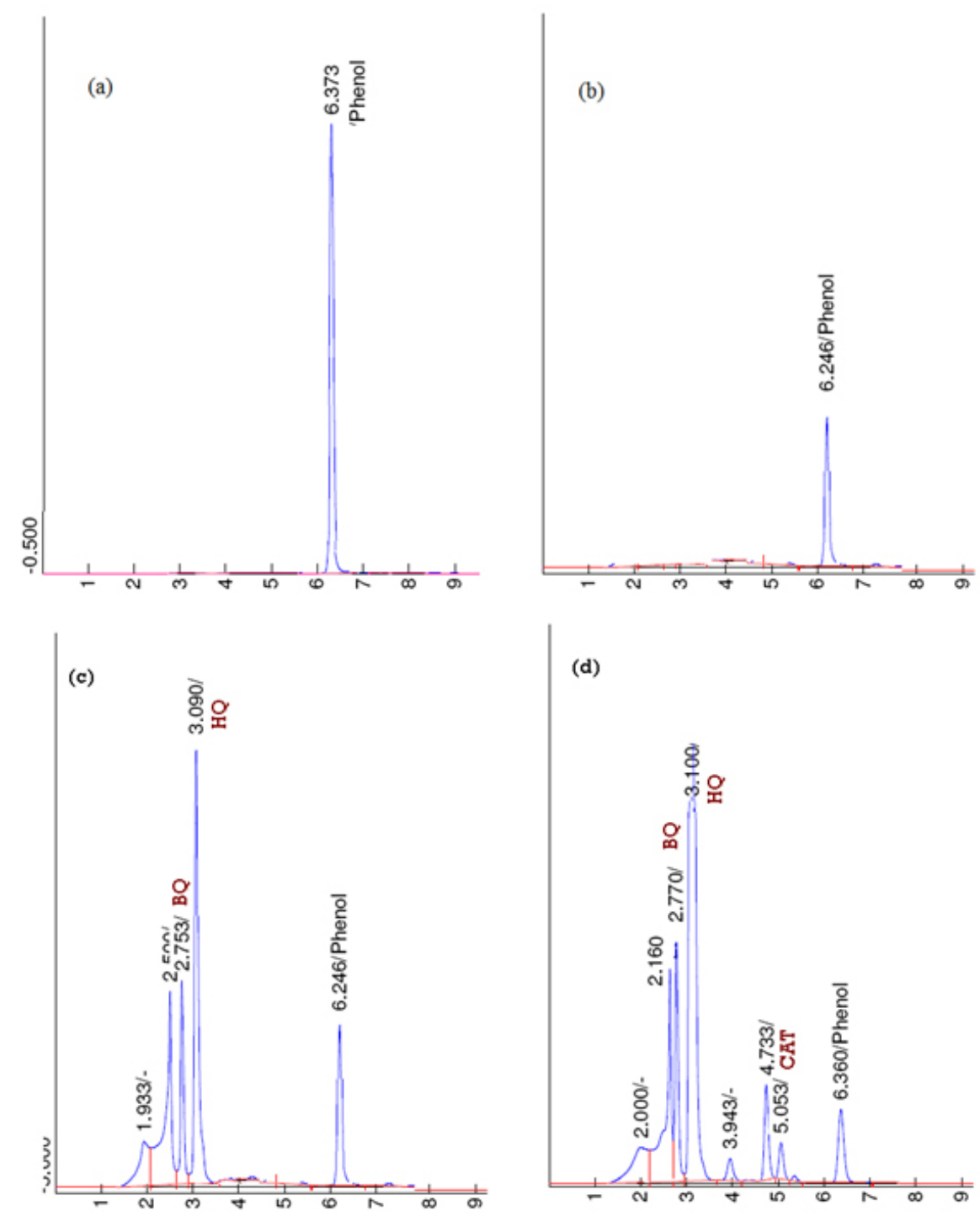

(d)

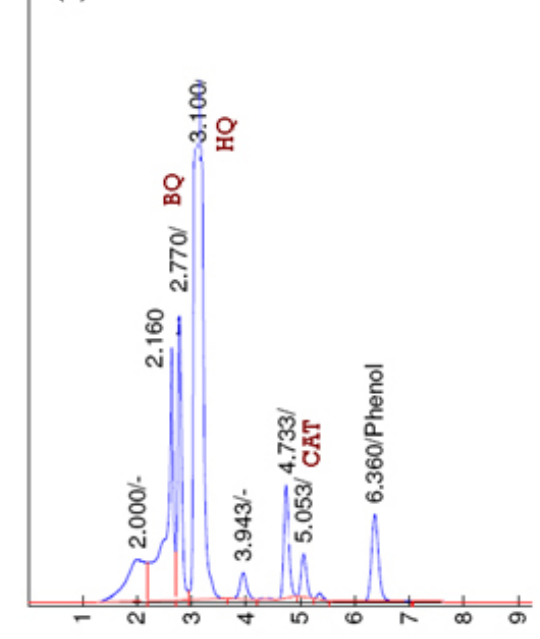

Fig. 8: Chromatogram of (a) initial solution (b) solution from adsorption treatment (c) solution from photooxidation treatment (d) solution from photocatalysis treatment (HQ: hydroquinone, CAT : catechol, $B Q$ : benzoquinone) 
photocatalysis the increasing phenol removal is found. It expresses the role of $\mathrm{ZnO}$ in attracting photon and producing the radicals. By comparing with phenol rate from photolysis process it is seen that phenol removal efficiency is encompassed and enhanced with the synergistic effect of both adsorption and photodegradation and with respect to the immobilization of $\mathrm{ZnO}$ on the porous structure of activated carbon ${ }^{6}$.

In advance the addition of $\mathrm{H}_{2} \mathrm{O}_{2}$ as oxidant enhance the rate. Theoretically phenol degradation in solution arises as a result of electron hole-pair formation upon irradiation of the semi-conducting oxide with appropriate light. In case recombination does not occur the electron can move to the surface of the zinc oxide as photoactive agent and combine with absorbed oxygen to form the $\mathrm{O}_{2}$ radicals. The produced electrons from the interaction leads to radicals and superadicals formation by the interaction with oxygen and $\mathrm{OH}$ from the solvent ${ }^{15}$. It has been well established that the presence of oxidant such as $\mathrm{H}_{2} \mathrm{O}_{2}$ in the solution will accelerate the radicals formation so the photooxidation has more sufficient reactant for phenol degradation compared to photocatalysis. From the varied photocatalyst in photocatalysis and photo-oxidation processes, it is concluded that $\mathrm{ZnO} / \mathrm{AC}-5.0$ has the best activity. The phenol removal from the solution also affects to the reduction of chemical oxygen demand(COD) as expressed in Fig.7b.

As the proof of different mechanism between photooxidation and photocatalysis is the chromatogram in Figure 8. The result of photooxidation and photocatalysis present the other peak as identification of products while adsorption show no other peak except phenol peak. From mass spectrometry analysis the results of photodegradation (photocatalysis and photooxidation) are identified as catechol (CAT) and hydroquinone (HQ) and benzoquione( $\mathrm{BQ}$ ) refer to following mechanism ${ }^{16,17}$ :

\section{Effect of $\mathrm{pH}$}

$\mathrm{pH}$ of solution is an important factor influencing the interaction between target molecule and also the photocatalyst. Effect of $\mathrm{pH}$ on initial rate of phenol degradation is depicted in Figure 9. From the curve it is concluded base solution increases the degradation rate. Even the zero poin charge of $\mathrm{ZnO}$ is 8.9 it is showed that at the $\mathrm{pH}$ lower than 8.9 for all catalyst sample the rate is not significantly

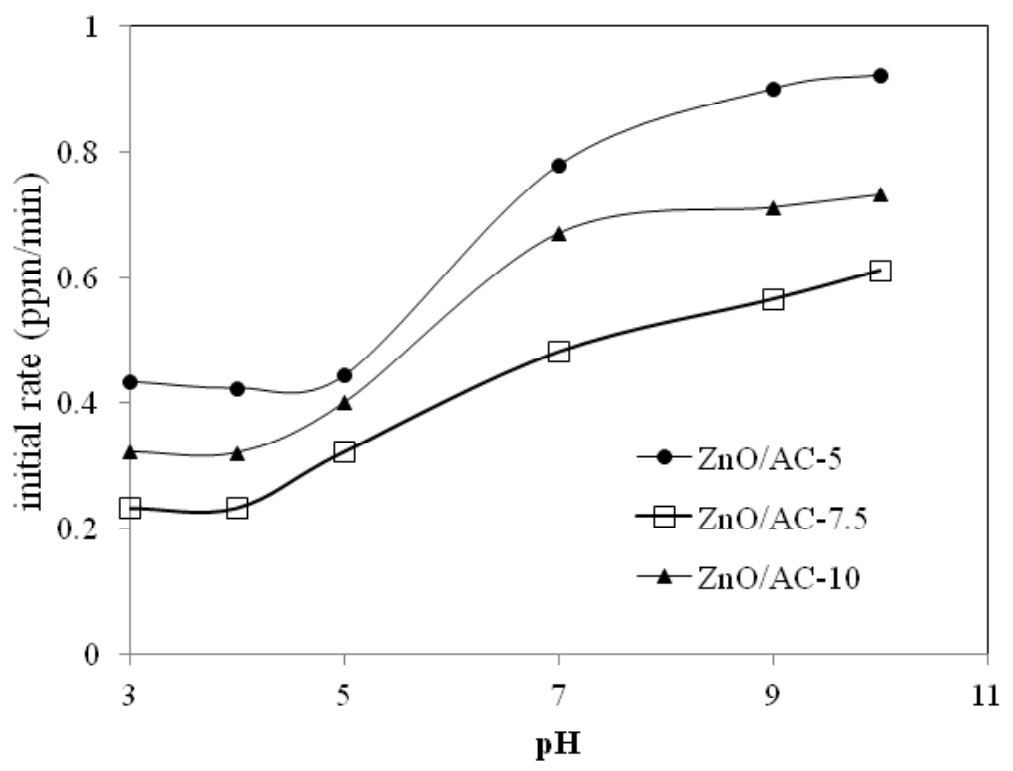

Fig. 9: Effect of $\mathrm{pH}$ on initial rate of phenol removal over photooxidation treatment (Condition: Catalyst dosage: $5 \mathrm{~g} / \mathrm{L}$; initial concentration: $10 \mathrm{ppm}, \mathrm{pH}=7$ ) 
different. The phenomenon is may related to the photocatalysis mechanism in that the presence of both $-\mathrm{OH}$ potentially accelerate the formation of radical and superadical for further oxidation step. In addition the base condition affects to catch $\mathrm{H}^{+}$ from phenol structure. Another possible reason to be confirmed is come from the possible adsorption of $\mathrm{OH}^{-}$onto the surface of the photocatalyst that favors to the formation of hydroxyl radicals, resulting in increasing phenol oxidation ${ }^{18}$.
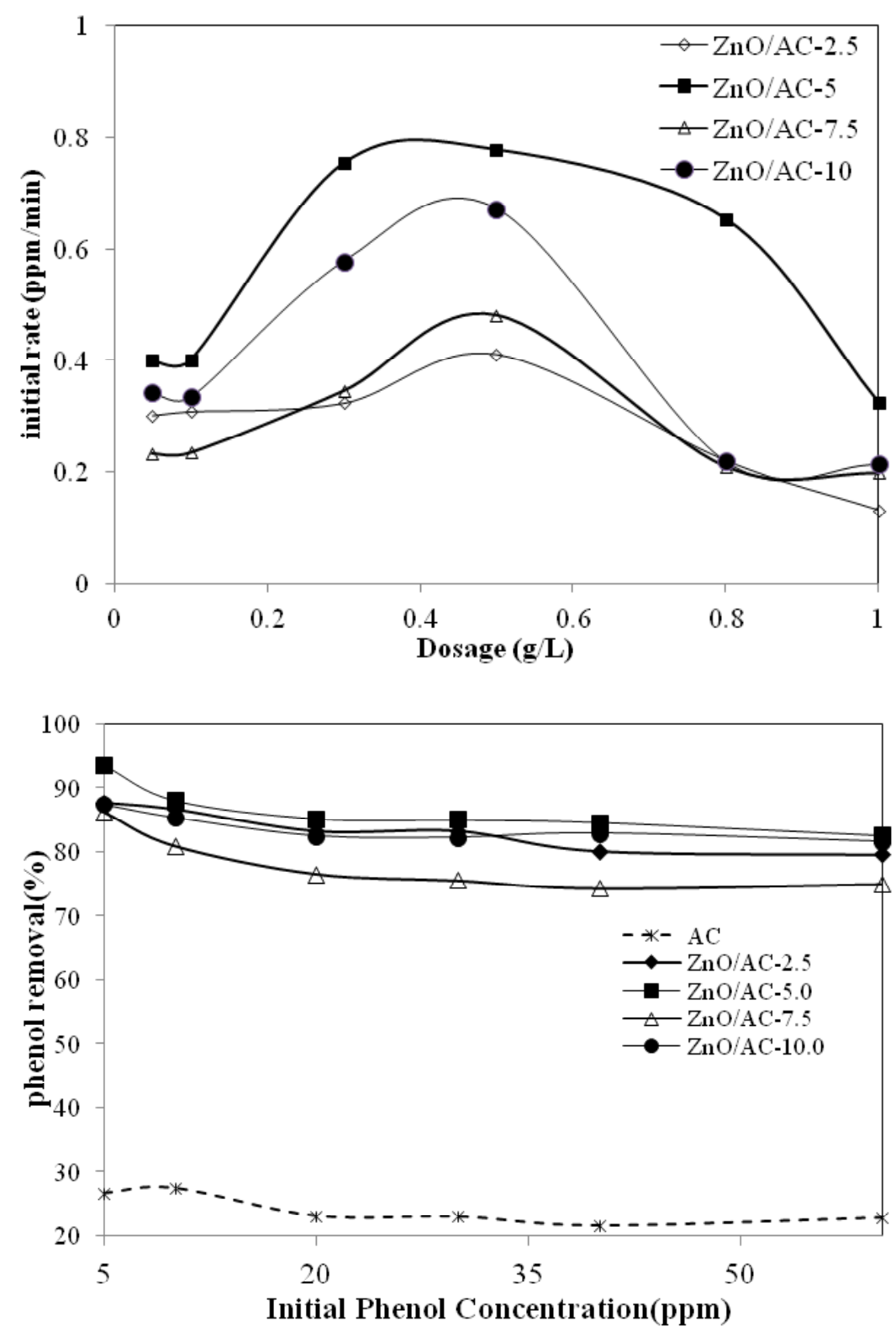

Fig.10: (a). Effect of catalyst dosage on initial rate of phenol removal over photooxidation treatment; (b) Effect of initial concentration on initial rate of phenol removal over photooxidation treatment (Condition: Catalyst dosage: $5 \mathrm{~g} / \mathrm{L} ; \mathrm{pH}=7$ ) 


\section{Effect of Catalyst Dosage}

Effect of catalyst dosage to the initial rate of phenol removal can be interpreted from curve in Figure 10a. Except for ZnO/AC-2.5, the photocatalysts exhibits the similar pattern of the influence of dosage to the initial rate of phenol removal. Initial rate of phenol removal is reach maximum at $0.5 \mathrm{~g} / \mathrm{L}$ indicating the optimum condition of photocatalysis system at the point. The possible reason for this is that the higher dosage give lower rate because of the limitation of light expose to the solution. The lower intensity of photon the lower rate of radicals formation. However in the utilization of $\mathrm{ZnO} / \mathrm{AC}-2.5$ the dosage seems to be insignificantly contribute to the increasing initial rate. The lowest content of $\mathrm{ZnO}$ in the photocatalyst the lower rate of radical formation obtained.

\section{Effect of Initial Concentration}

Degradation rate of phenol decreases with increasing initial concentration as shown in Figure $10 \mathrm{~b}$. The trend is usually found in such organic molecule photooxidation due to generally at higher amount of phenol molecules in solution the more radicals required to make oxidation complete. In relation with the data in Table 2 and the effect of $\mathrm{pH}$ it is also confirmed that $\mathrm{ZnO} / \mathrm{AC}-5$ give the highest activity.
By confirmation with physicochemical character of photocatalyst what can be concluded is the activity of photocatalyst is influenced by the combination of parameters factor. The highest activity was achieved by $\mathrm{ZnO} / \mathrm{AC}-5.0$ while it has similar band gap energy value with other catalysts and it also neither the highest amount of $\mathrm{Zn}$ nor the highest specific surface area. The photocatalyst with the highest amount of $\mathrm{ZnO}(\mathrm{ZnO} / \mathrm{AC}-10)$ does not give the highest activity probably due to its lower specific surface area among other and has the lower band gap energy values.

\section{CONCLUSION}

The study presents the preparation of ZnO/ACs expressing photocatalytic activity in phenol removal by photocataysis mechanism. The dispersion give effect to reduce specific surface area of activated carbon and as higher $\mathrm{Zn}$ content, $\mathrm{ZnO}$ phase is identified. Photocatalytic testing in phenol removal revealed that the specific surface area, band gap energy and Zn content parameters are not individually related to the increasing activity but it is affected by the combination of those parameters. Further photocatalytic modeling is required to get the quantitative relationship.

\section{REFERENCES}

1. Bagabas, A.; Alshammari, A.; Aboud, M.F.A.; Kosslick H.; Nanoscale.res.lett., 2013, 8, 516525.

2. Andriantsiferana, C.; Mohamed, E.; Farouk, H. Delmas; Environ. Technol., 2013, 35, 1-9.

3. Kyzas, G.Z.; Fu, J.; Matis, K.A.; Materials, 2013, 6,11, 312-337.

4. Sobana, N.; Thirumalai, K.; Canadian Chem. Trans., 2016, 4, 77-89.

5. Johar, M.A.; Afzal, R.A.; Alazba, A.A.; Manzoor, U.; Nanocomposites, 2015, 1-22.

6. Muthirulan, P.; Meenakshisundararam, M.; Kannan, N.; JAdv Res., 2013, 4, 479-484.

7. Pung, S.Y. ; Lee, W.P.; Aziz, A.; Int. J. Inorg. Chem., 2012, 1-9.

8. Yassýtepe, E.; Yatmaz, H.C.; Öztürk, C.; Öztürk, K.; Durana, C.; J. Photochem.
Photobiol. A, 2018, 198, 1-6..

9. Daneshvar, N.; Salari, D., ; J.Photochem. Photobiol. A, 2004, 162, 317-322.

10. Forgács, E.; Cserháti, T.; Oros, G.; Environ Int., 2014, 30, 953-971.

11. Velasco, L.F.; Para,J.B.; Ania, C.O.; Appl. Surf. Sci., 2010, 256, 5254-5258.

12. Asiltürk, M.; Aener, A.; Chem.Eng.J, 2012, 180, 354-363.

13. Zhao, J.; Yang, L.; Li, F.; Yu, R.; Jin, C.; Carbon, 2008, 7, 744-751.

14. Jradi, K.; Maury, C.; Daneault, C.; Appl.Sci, 2015, 5(4), 1164-1183.

15. Sathe, P.; Myint, M.T.Z.; Dobretsov, S.; Dutta, J.; Sep.Pur.Technol., 2016, 162, 61-67.

16. Grabowska, E.; Reszczyñska, J.; Zaleska, A.; Water Res., 2014, 17(46AD), 5453-5471. 
17. Velasco, L.F.; Carmonaa, R.J.; Matos, J.; Ania, $\quad 18 . \quad$ Soltani, R.D.C.; Rezaee, A.; Khataee, A.; C.O.; Carbon. 2015, 206(73AD),206-2015. Safari, M.; J. Ind. Eng.Chem., 2014, 20, 18611868. 